\title{
Transient Stability of Voltage-Source Converters using Grid-Forming Virtual Inertia Control
}

\author{
Salem Alshahrani ${ }^{1 *}$ and Mohammed Abido ${ }^{1,2}$ \\ ${ }^{1}$ Electrical Engineering Department, King Fahd University of Petroleum \& Minerals (KFUPM) \\ Dhahran 31261, Saudi Arabia \\ 2 K.A.CARE Energy Research \& Innovation Center, Dhahran 31261, Saudi Arabia \\ *g200083570@kfupm.edu.sa
}

\begin{abstract}
The shift in power generation towards renewable energy (RE) resources interfaced with power electronic-based converters decrease the overall system inertia. The logical solution is to increase the synchronous machines number, but an alternative approach is to use grid-forming converter. The virtual synchronous generator (VSG) is one of the grid-forming converter control schemes that mimics the synchronous generator, so it improves the system inertial response. This paper, offers a comparative case study of synchronous generators versus VSGs that are simulated using power system computer aided design (PSCAD) software.
\end{abstract}

Index Terms-Grid-forming converter; renewable energy; synchronous generator; transient stability; virtual inertia

\section{INTRODUCTION}

Renewable energy ( $\mathrm{RE}$ ) resources integration rises steadily around the globe [1]. The network that comprises different distributed generation (DG) sources, battery energy storage system (BESS), and controllable loads is known as a micorgrid (MG) that is formed to improve the integration process of such DGs in terms of stability performance [2]. The MG uses two types of converters to interface with DGsnamely, grid-forming converter and grid-following converter [3]. The grid following converter simply regulates the power exchanged with the MG, whereas the grid-forming converter the MG voltage and frequency [4].

The exchanged power between different DGs is controlled via the droop controller that resembles the conventional synchronous generator functionality. The droop control technique was used first at the uninterruptible power supply (UPS) systems that consist of many grid-forming units [5. 6. 7]. The local loads supplied from UPS share similar impedance for load lines, but this is not the case for the MG. An MG that is composed of several parallel converters with their respective loads has very much different line impednaces that are dominantly resistive, so the MG system voltage and frequency is significantly affected.

The power-speed droop control is generalized to include the parallel converter-based generating units in the MG, but this entails several problems since the associated line impedances are mainly resistive, which cause several operational issues [8, 9]. As a result, many studies came out to improve the problematic operation in the droop controller of the parallel standalone converter-based in MGs. A powervoltage droop controller was proposed instead of the conventional power-speed droop controller in order to tackle the

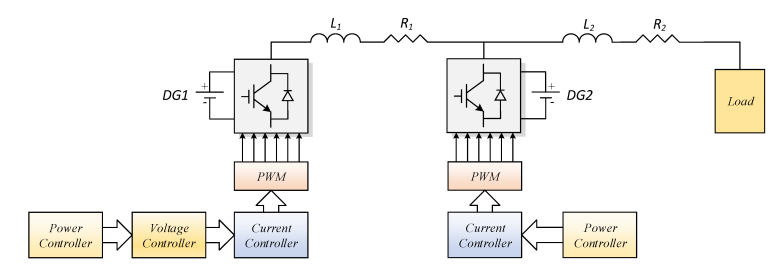

Fig. 1. Structure of converter-based distributed generation in MG system. 18

inaccuracy in the reactive power sharing [10]. Additionally, a virtual impedance was included in the model so as to imitate the line impedance inductor [11]. Decoupling the relationship between the active power and reactive power to enhance the system performance was the main tool proposed by [12] through a virtual frame transformation. The adaptive decentralized droop controller works to enhance power oscillation by preservation of the power sharing stability [13]. Soft computing techniques were utilized in optimizing the droop coefficient with particle swarm optimization (PSO) to improve the overall system stability [14].

Regardless of the widespread usage of the droop controller, it still has some drawbacks. The inertiae contributed by synchronous generators are critical to maintain the system stability. However, the common problem in MGs is the lack of sufficient inertia, especially if there is a large integration rate or REs [15]. Consequently, large signal disturbances would destabilize the system voltage and frequency to the point where might be there a total blackout of connected generators [16, 17]. Virtual synchronous generator (VSG) was introduced to resolve the low inertia problem [19]. The overall MG inertia is increased through imitation of the steady state behavior as well as transient behavior of synchronous generators [20]. The authors in [21] provided a detailed system analysis of the VSG, concluding with the superiority of the VSG compared to the droop controller. Many studies proposed utilization of VSG to both gridfeeding converters and grid-forming converters [22, 23]. For instance, grid-feeding converters can have an energy buffer so as to reduce power fluctuations using the VSG technique [24]. Grid-forming converters, also, can have an enhanced transient response through a modification of the VSG with frequency deviations [25]. A detailed design and analysis 
of the VSG controller is offered in [26, 27]. That being said, the transient response, overshoot in particular, is much higher in case of presence of both converters at the same MG, compared to MGs having only one converter type. This is attributed to the different response times of the two converters [28].

In previous studies, the transient response of the converters were not taken into consideration in the two controlling schemes: droop and VSG. The model proposed in [29] is employed to simulate the IEEE-9 bus system in all gridforming case and all synchronous generators case for a comparison purpose. A large signal analysis is used to test the transient response in the two scenarios, which is a threephase-to-ground fault at the common bus.

The remainder of the paper is organized as follows. Section 【 Iiscusses technical control framework. The case study proposed is described in Section III and the conclusion is in Section IV.

\section{CONVERTER-BASED GENERATION}

Converter-based DG is classified into: a grid-feeding converter and a grid-forming converter. The grid-feeding converter is a current source that is connected across a parallel high impedance to a network to control the power exchange between the converter and the grid. That being said, it has no control over the grid voltage nor frequency, so it cannot operate as such since it needs a synchronous generator or any other kinds of converters. The grid-forming converter, on the other hand, is a voltage source connected to the grid through a series low impedance. Also, it regulates the grid voltage and frequency in a standalone operation as opposed to its counterpart the grid-feeding converter. Therefore, the grid-forming converter functions as a voltage reference for grid-feeding converters. The structures of the two converters are shown in Fig. 1, where the DG source can be a PV, a wind power, a battery energy storage system, or otherwise. This DG is connected to the AC grid through the underlying converter. The converter is connected to the MG through an inductor $\left(L_{f}\right)$ and a capacitor $\left(C_{f}\right)$ that form an output LC filter of the VSG.

\section{A. Grid-forming converter}

The grid-forming control scheme is classified into three cascaded controllers: power controller, voltage controller, and current controller as depicted in Fig. 2. Active power and reactive power controllers dorm what is known as outer controller in which the reference angle and the reference voltage are generated. The VSG controller handles the active power controller to yield the reference angle, and the droop controller is adopted to control the reactive power controller to regulate the reference voltage amplitude value $E^{*}$. The reference output voltage $V_{a b c}^{*}$ that is regulated from the power controller is computed as per the following equations:

$$
\begin{gathered}
V_{a}^{*}=E^{*} \cos (\theta) \\
V_{b}^{*}=E^{*} \cos (\theta+(2 \pi / 3))
\end{gathered}
$$

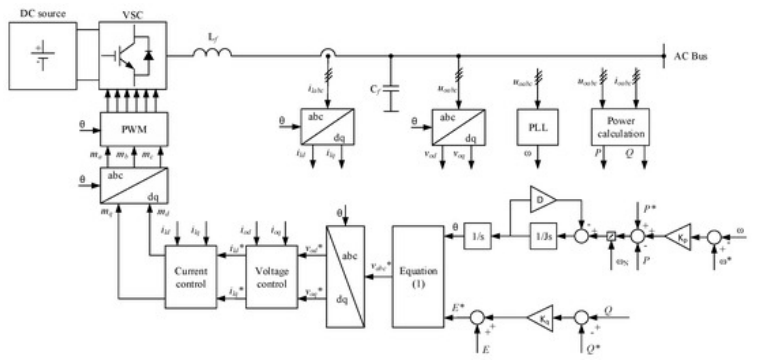

Fig. 2. Control scheme of the virtual synchronous generator control-based grid-forming converter. 29]

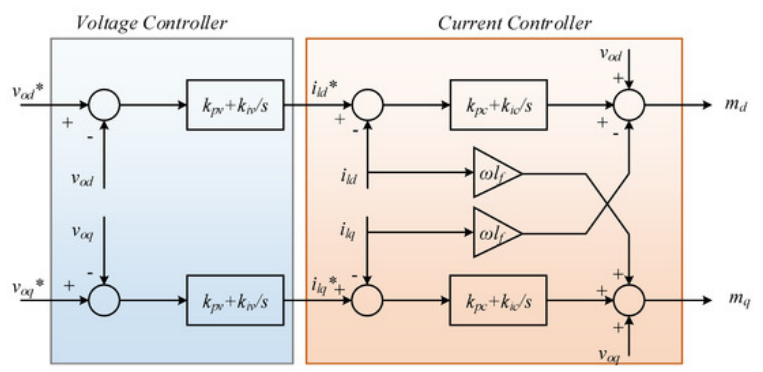

Fig. 3. Control scheme of inner controller. 29]

$$
V_{c}^{*}=E^{*} \cos (\theta-(2 \pi / 3))
$$

This output voltage reference is transformed into dq frame before going through the inner loop controllers (i.e. voltage controller and current controller). The voltage controller regulates the magnitude of the voltage set by the VSG controller, while the current controller runs to match the supplied current by the VSG controller to its reference value. The detailed structure of the inner loop controllers is shown in Fig. 4, where the the current controller reference value $\left(i_{l d}^{*}\right)$ and the measured current value $\left(i_{l d}\right)$ that passes through the inductor filter $\left(L_{f}\right)$ are compared to generate an error signal that is entered into a proportional-integral (PI) controller. The modulating signal of the pulse width modulation (PWM) is the output of the current controller that is used to control the switching time of the insulated gate bipolar transistor (IGBT) switches. The following equations are used to calculate the current controller modulating signal output:

$$
\begin{aligned}
& m_{d}=v_{o d}-\omega i_{l q} L_{f}+k_{p c}\left(i_{l d}^{*}-i_{l d}\right)+\int k_{i c}\left(i_{l d}^{*}-i_{l d}\right) d t \\
& m_{q}=v_{o q}-\omega i_{l d} L_{f}+k_{p c}\left(i_{l q}^{*}-i_{l q}\right)+\int k_{i c}\left(i_{l q}^{*}-i_{l q}\right) d t
\end{aligned}
$$

Where $k_{i c}$ and $k_{p c}$ are the integral and proportional gains and $m_{d}$ and $m_{q}$ are the modulating signals in the dq frame. The voltage controller, on the other hand, controls the MG output voltage. Again, the voltage controller enters the voltage error signal to a PI controller to set the current controller reference values $\left(i_{l d}^{*} i_{l q}^{*}\right)$ as depicted in Fig. 4 . The equations 


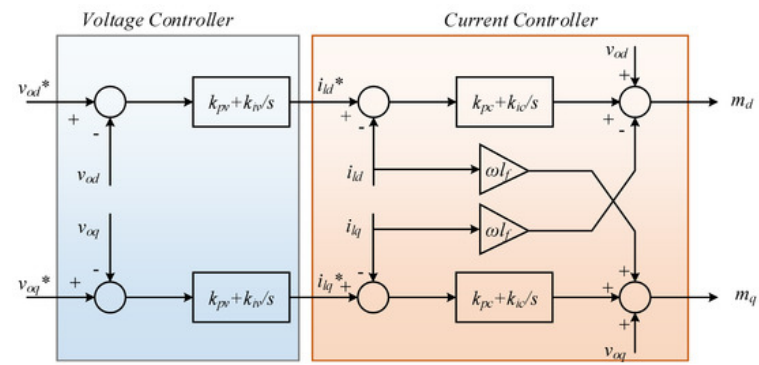

Fig. 4. Control scheme of inner controller. 29

governing the voltage controller are as follows:

$$
\begin{aligned}
& i_{l d}^{*}=k_{p v}\left(v_{o d}^{*}-v_{o d}\right)+\int k_{p c}\left(v_{o d}^{*}-v_{o d}\right) d t \\
& i_{l q}^{*}=k_{p v}\left(v_{o q}^{*}-v_{o q}\right)+\int k_{p c}\left(v_{o q}^{*}-v_{o q}\right) d t
\end{aligned}
$$

Where $k_{i v}$ and $k_{p v}$ are the integral and proportional gains of the voltage controller. The reactive power controller employs the conventional droop controller in order to determine the reactive power amount to be injected into the grid in accordance with the varying $\mathrm{AC}$ voltage. The control scheme is shown i Fig. 5 that indicates the reactive power controller output is the voltage controller reference value that is given in (88). The $\mathrm{AC}$ voltage and the reactive power are linked through a droop coefficient that is defined in 9 ).

$$
\begin{gathered}
E^{*}=E-K_{q}\left(Q^{*}-Q\right) \\
K_{q}=\frac{V_{\max }-V_{\min }}{Q_{\max }-Q_{\min }}
\end{gathered}
$$

The active power controller utilizes the conventional synchronous generator virtual control scheme depicted in Fig. 5 in which the swing equation can be derived as shown in (10).

$$
\begin{gathered}
P_{m}=P+J \omega_{N} \frac{d \omega}{d t}+D \omega_{N}\left(\omega-\omega_{N}\right) \\
\frac{d \theta}{d t}=\omega
\end{gathered}
$$

Where $P_{m}$ is the governor generated mechanical power, $\mathrm{P}$ is the active power measured at the converter side, $\mathrm{J}$ is the virtual inertia, D is the damping factor, $\omega$ is the angular frequency, $\omega_{N}$ is the system rated angular frequency, and $\theta$ is the electrical angle.

The mechanical power $P_{m}$ generated from the governor is as 12.

$$
\left(\omega^{*}-\omega\right)=-k_{p}\left(P^{*}-P_{m}\right)
$$

Where $P^{*}$ and $\omega^{*}$ are the reference values of power and angular frequency, respectively.

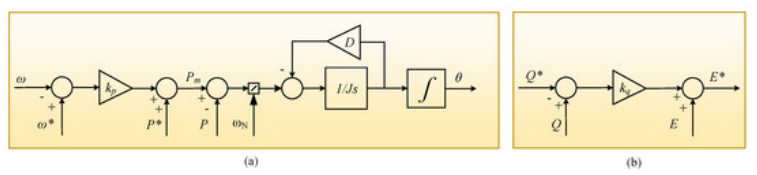

Fig. 5. Control scheme: (a) virtual synchronous generator (VSG) controller; (b) Q-V droop controller. [29]

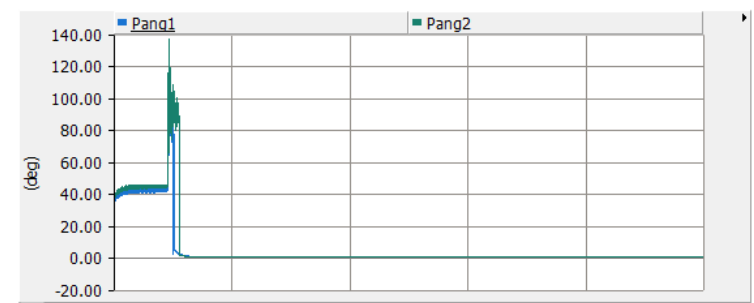

Fig. 6. Rotor angle of synchronous machine-based case

\section{A CASE STUDY}

A system-level simulation using power system computer aided design (PSCAD) software for the IEEE-9 bus system, illustrated in Fig. 8, to test the system transient stability in case of a three-line-to-ground fault that represents the worst case scenario. The system base voltage, frequency, and power are listed in Table \

The system simulation is conducted for two different cases: all synchronous generators and all grid-forming converters. The transient response of each scenario is obtained and a compared in terms of stability performance. In fact, the conventional power-speed droop controller is for synchronous generators is in direct comparison with the modified virtual-inertia-based VSG controller for the grid-forming converter. The virtual inertia impact on the system transient stability will be investigated.

The simulated network is shown in Fig. 10 and Fig. 11

TABLE I

SYSTEM PARAMETERS

\begin{tabular}{|l|l|}
\hline Parameter & Value \\
\hline$V_{n}$ & $230 \mathrm{kV}$ \\
\hline$V_{D C}$ & $640 \mathrm{kV}$ \\
\hline $\mathrm{f}$ & $60 \mathrm{~Hz}$ \\
\hline Virtual inertia & $32 \mathrm{~kg} \cdot \mathrm{m}^{2}$ \\
\hline Virtual damping & 50 \\
\hline
\end{tabular}




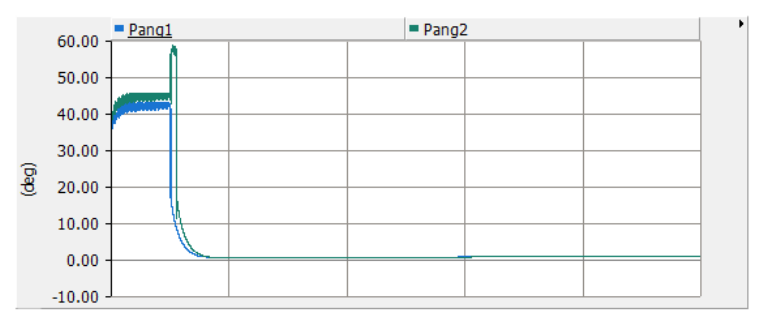

Fig. 7. Rotor angle of grid-forming-based case

that depict the synchronous generator-based and the gridforming-based configurations, respectively. The synchronous machines reside in two buses while the slack bus is represented as a voltage source behind impedance. The DC side is assumed to be constant so as to eliminate the RE intermittent behavior. This because the main objective is to analyze the transient stability with no intervening factors.

Moreover, the details of the grid-forming converter are illustrated in Fig. 9 that comprises a two-level insulatedgate bipolar transistor (IGBT) that is connected to the fixed DC voltage and interfaced with the $\mathrm{AC}$ side through these inverters. The control schemes discussed above are all implemented to mimic the synchronous generator functionality so as to stabilize the given system.

The tested two cases were subjected to a three-phase fault applied at $450 \mathrm{~ms}$ and lasted $250 \mathrm{~ms}$. The rotor angles behavior are observed in both cases, which are seen in Fig. 6 and Fig. 7 Seemingly, the grid-forming-based case shows a drastic reduction in overshoot, roughly $50 \%$, with the given virtual inertia and virtual damping coefficient. Furthermore, the grid-forming converter shows a smoother transition. Nevertheless, there is still small fluctuation at the peak, which can be attributed to the virtual inertia dynamics as noticed in $(10)$.

The virtual inertia is a double-edged sword. A high value of that virtual inertia would provide more damping, but it would increase the overshooting. This the reason the virtual damping coefficient $\mathrm{D}$ is utilized in the control scheme to improve the system performance in conjunction with a relatively small virtual inertia value. Having adopted a high virtual inertia, the system can become unstable.

\section{CONCLUSION}

$\mathrm{RE}$ resources integration at large capacities introduce many challenges, stability in particular. One of the biggest challenges is the reduction in system inertia, thereby degrading the stability performance. The grid-forming converter offers a promising approach to tackle this problem even for no synchronous machines available. In this paper, a selected control scheme to adopt VSG that injects virtual inertia and damping factor so as to help stabilizing the given system in case of experiencing faults. The effectiveness of the gridforming converter was shown by comparing the two cases simulation, and the trad-off between the virtual inertia and the virtual damping factor is emphasized. 


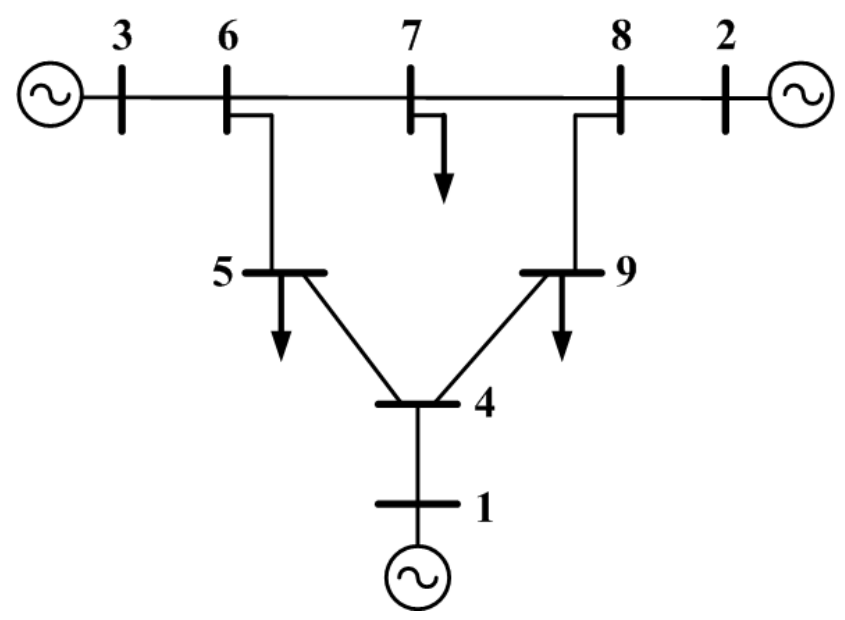

Fig. 8. IEEE 9-bus test system

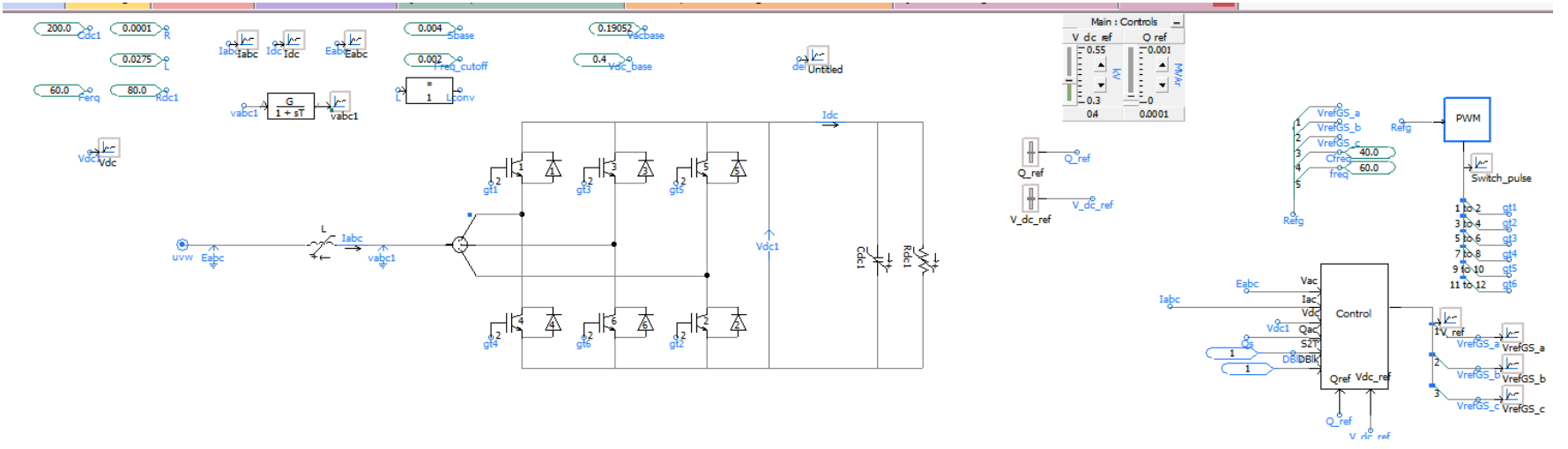

Fig. 9. Grid-forming converter internal components 


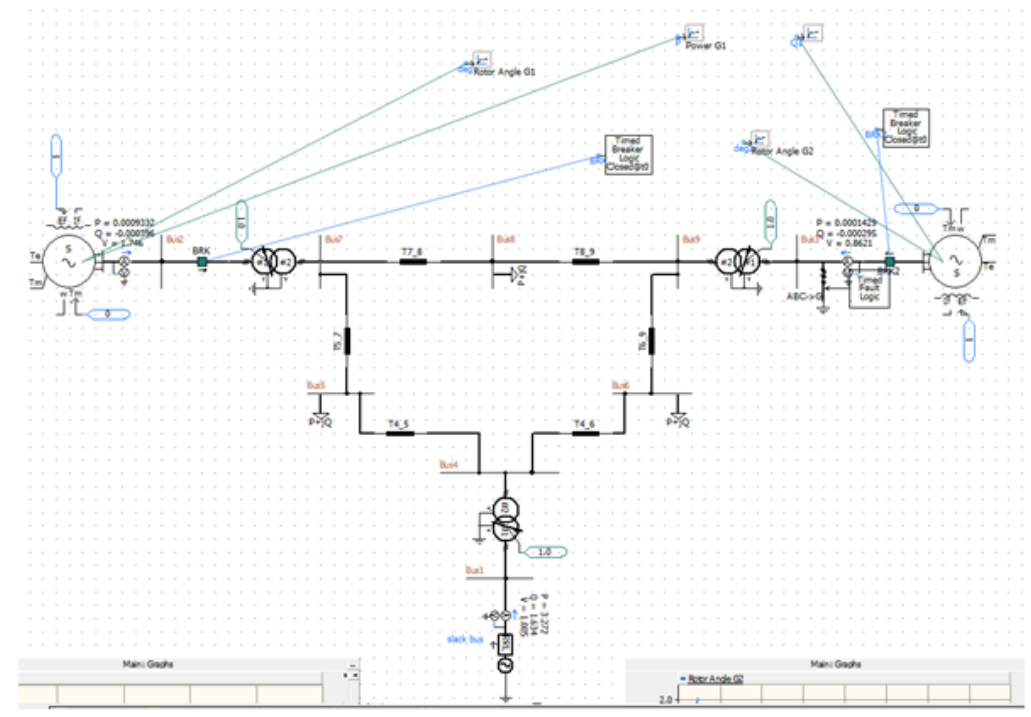

Fig. 10. IEEE 9-bus synchronous machine-based test system

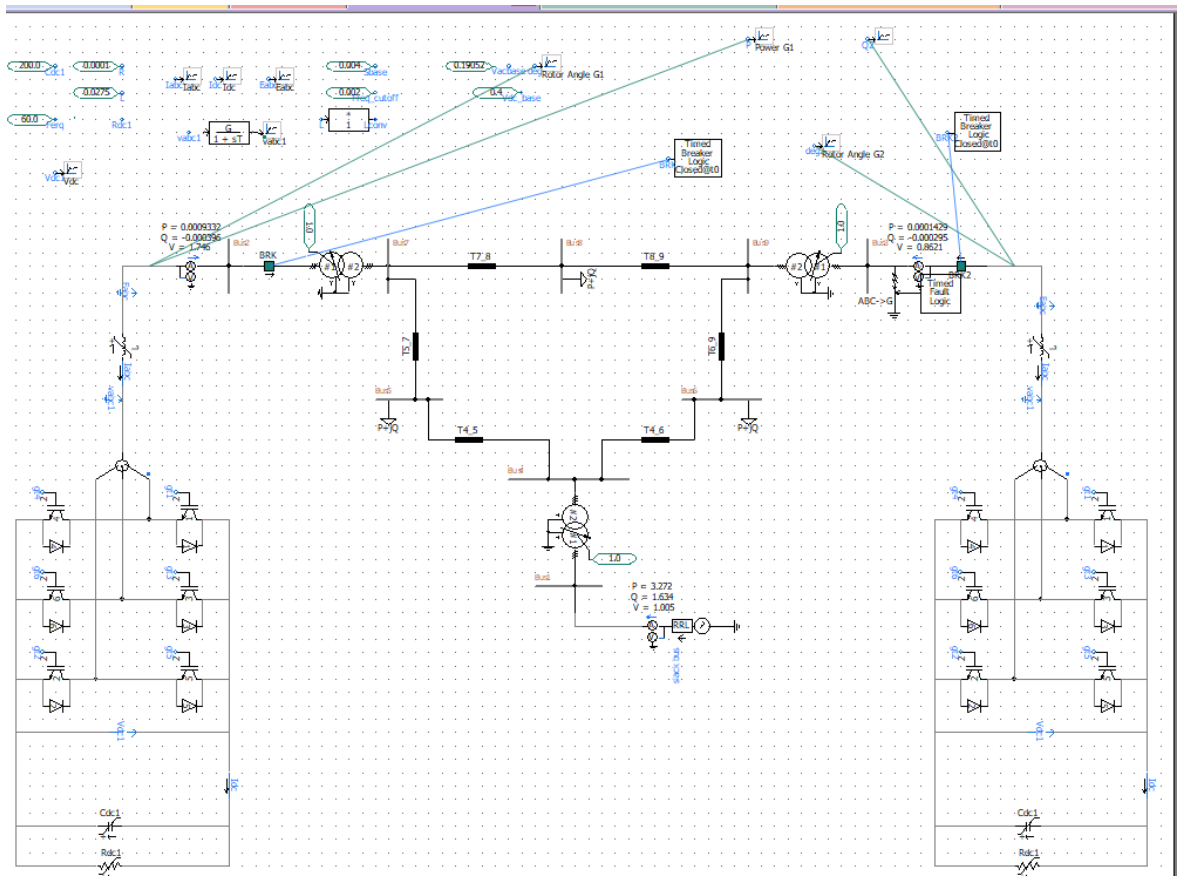

Fig. 11. IEEE 9-bus grid-forming-based test system 


\section{REFERENCES}

[1] C. Cecati, H. A. Khalid, M. Tinari, G. Adinolfi, and G. Graditi, "Dc nanogrid for renewable sources with modular dc/dc llc converter building block," IET Power Electronics, vol. 10, no. 5, pp. 536-544, 2016.

[2] N. Hatziargyriou, H. Asano, R. Iravani, and C. M. Marnay, "Ieee power energy mag," 2007.

[3] J. Rocabert, A. Luna, F. Blaabjerg, and P. Rodriguez, "Control of power converters in ac microgrids," IEEE transactions on power electronics, vol. 27, no. 11, pp. 4734-4749, 2012.

[4] N. Pogaku, M. Prodanovic, and T. C. Green, "Modeling, analysis and testing of autonomous operation of an inverter-based microgrid," IEEE Transactions on power electronics, vol. 22, no. 2, pp. 613-625, 2007.

[5] J. M. Guerrero, L. G. De Vicuna, J. Matas, M. Castilla, and J. Miret, "Output impedance design of parallelconnected ups inverters with wireless load-sharing control," IEEE Transactions on industrial electronics, vol. 52, no. 4, pp. 1126-1135, 2005.

[6] J. M. Guerrero, L. Hang, and J. Uceda, "Control of distributed uninterruptible power supply systems," IEEE Transactions on Industrial Electronics, vol. 55, no. 8, pp. 2845-2859, 2008.

[7] M. C. Chandorkar, D. M. Divan, and R. Adapa, "Control of parallel connected inverters in standalone ac supply systems," IEEE transactions on industry applications, vol. 29, no. 1, pp. 136-143, 1993.

[8] J. P. Lopes, C. Moreira, and A. Madureira, "Defining control strategies for microgrids islanded operation," IEEE Transactions on power systems, vol. 21, no. 2, pp. 916-924, 2006.

[9] D. E. Olivares, A. Mehrizi-Sani, A. H. Etemadi, C. A. Cañizares, R. Iravani, M. Kazerani, A. H. Hajimiragha, O. Gomis-Bellmunt, M. Saeedifard, R. PalmaBehnke, et al., "Trends in microgrid control," IEEE Transactions on smart grid, vol. 5, no. 4, pp. 19051919, 2014.

[10] Y. Li and Y. W. Li, "Power management of inverter interfaced autonomous microgrid based on virtual frequency-voltage frame," IEEE Transactions on Smart Grid, vol. 2, no. 1, pp. 30-40, 2011.

[11] J. He and Y. W. Li, "Analysis, design, and implementation of virtual impedance for power electronics interfaced distributed generation," IEEE Transactions on industry Applications, vol. 47, no. 6, pp. 2525-2538, 2011.

[12] J. C. Vasquez, J. M. Guerrero, M. Savaghebi, J. EloyGarcia, and R. Teodorescu, "Modeling, analysis, and design of stationary-reference-frame droop-controlled parallel three-phase voltage source inverters," IEEE Transactions on Industrial Electronics, vol. 60, no. 4, pp. 1271-1280, 2012.

[13] Y. A.-R. I. Mohamed and E. F. El-Saadany, "Adaptive decentralized droop controller to preserve power sharing stability of paralleled inverters in distributed generation microgrids," IEEE Transactions on Power Electronics, vol. 23, no. 6, pp. 2806-2816, 2008.

[14] K. Yu, Q. Ai, S. Wang, J. Ni, and T. Lv, "Analysis and optimization of droop controller for microgrid system based on small-signal dynamic model," IEEE Transactions on Smart Grid, vol. 7, no. 2, pp. 695-705, 2015.

[15] H. Han, X. Hou, J. Yang, J. Wu, M. Su, and J. M. Guerrero, "Review of power sharing control strategies for islanding operation of ac microgrids," IEEE Transactions on Smart Grid, vol. 7, no. 1, pp. 200-215, 2015.

[16] X. Feng, "Dynamic balancing for low inertia power systems," in 2013 IEEE Power \& Energy Society General Meeting, IEEE, 2013, pp. 1-5.

[17] X. Tang, W. Deng, and Z. Qi, "Investigation of the dynamic stability of microgrid," IEEE Transactions on Power Systems, vol. 29, no. 2, pp. 698-706, 2013.

[18] D. Pan, X. Wang, F. Liu, and R. Shi, “Transient stability of voltage-source converters with grid-forming control: A design-oriented study," IEEE Journal of Emerging and Selected Topics in Power Electronics, 2019.

[19] Q.-C. Zhong and G. Weiss, "Synchronverters: Inverters that mimic synchronous generators," IEEE transactions on industrial electronics, vol. 58, no. 4, pp. 1259-1267, 2010.

[20] Q.-C. Zhong, P.-L. Nguyen, Z. Ma, and W. Sheng, "Self-synchronized synchronverters: Inverters without a dedicated synchronization unit," IEEE Transactions on power electronics, vol. 29, no. 2, pp. 617-630, 2013.

[21] J. Liu, Y. Miura, and T. Ise, "Comparison of dynamic characteristics between virtual synchronous generator and droop control in inverter-based distributed generators," IEEE Transactions on Power Electronics, vol. 31, no. 5, pp. 3600-3611, 2015.

[22] H. Zhao, Q. Yang, and H. Zeng, "Multi-loop virtual synchronous generator control of inverter-based dgs under microgrid dynamics," IET Generation, Transmission \& Distribution, vol. 11, no. 3, pp. 795-803, 2017.

[23] Y. Hirase, K. Sugimoto, K. Sakimoto, and T. Ise, "Analysis of resonance in microgrids and effects of system frequency stabilization using a virtual synchronous generator," IEEE Journal of Emerging and Selected Topics in Power Electronics, vol. 4, no. 4, pp. 1287-1298, 2016.

[24] M. Van Wesenbeeck, S. De Haan, P. Varela, and K. Visscher, "Grid tied converter with virtual kinetic storage," in 2009 IEEE Bucharest PowerTech, IEEE, 2009, pp. 1-7.

[25] N. Soni, S. Doolla, and M. C. Chandorkar, "Improvement of transient response in microgrids using virtual inertia," IEEE transactions on power delivery, vol. 28, no. 3, pp. 1830-1838, 2013. 
[26] H. Wu, X. Ruan, D. Yang, X. Chen, W. Zhao, Z. Lv, and Q.-C. Zhong, "Small-signal modeling and parameters design for virtual synchronous generators," IEEE Transactions on Industrial Electronics, vol. 63, no. 7, pp. 4292-4303, 2016.

[27] S. D’Arco, J. A. Suul, and O. B. Fosso, “A virtual synchronous machine implementation for distributed control of power converters in smartgrids," Electric Power Systems Research, vol. 122, pp. 180-197, 2015.

[28] O. Palizban, K. Kauhaniemi, and J. M. Guerrero, "Microgrids in active network management-part i: Hierarchical control, energy storage, virtual power plants, and market participation," Renewable and Sustainable Energy Reviews, vol. 36, pp. 428-439, 2014.
[29] C.-K. Nguyen, T.-T. Nguyen, H.-J. Yoo, and H.-M. $\mathrm{Kim}$, "Improving transient response of power converter in a stand-alone microgrid using virtual synchronous generator,' Energies, vol. 11, no. 1, p. 27, 2018.

[30] R. Doherty, A. Mullane, G. Nolan, D. J. Burke, A. Bryson, and M. O'Malley, "An assessment of the impact of wind generation on system frequency control," IEEE transactions on power systems, vol. 25, no. 1, pp. 452-460, 2009.

[31] G. Delille, B. Francois, and G. Malarange, "Dynamic frequency control support by energy storage to reduce the impact of wind and solar generation on isolated power system's inertia," IEEE Transactions on sustainable energy, vol. 3, no. 4, pp. 931-939, 2012. 